\title{
Spontaneous rupture of the spleen in early pregnancy
}

\author{
A. J. LAMERTON \\ F.R.C.S., M.R.C.P. \\ St Mary's Hospital, London W2
}

\begin{abstract}
Summary
Spontaneous rupture of the spleen as a result of laceration by a rib exostosis is described. This unusual case serves to underline the diagnostic difficulties of the acute abdomen in pregnancy.
\end{abstract}

KEY WORDS: acute abdomen, spleen rupture.

\section{Introduction}

Traumatic and spontaneous rupture of the normal (Orloff and Peskin, 1958) and pathological spleen, including those occurring during pregnancy (Sparkman, 1958; Buchsbaum, 1969) have been described. A rib exostosis as a cause of spontaneous rupture has not previously been reported.

\section{Case report}

A 32-year-old housewife was admitted in 1977 as an emergency with a short history of severe left-sided pleuritic pain which had occurred suddenly while she was resting. There was radiation to the left shouldertip but no cough, dyspnoea, or haemoptysis. She had vomited once. The patient was known to be 14 weeks pregnant.

She had undergone a caesarian section at term 4 years previously for fetal distress.

On examination, she was apyrexial with a pulse of $84 / \mathrm{min}$, blood pressure of $110 / 60 \mathrm{mmHg}$, and respiratory rate of $18 / \mathrm{min}$. There was reduced expansion at the left chest base with crepitations and a pleural rub. In the upper abdomen there was tenderness to deep palpation, but no signs of peritonitis.

A gynaecologist confirmed a normal 14-weeks intrauterine pregnancy. Blood screen, urine microscopy and electrocardiography were normal. X-rays of the chest and abdomen were not performed because of risk to the fetus. A diagnosis of pulmonary embolism was made. Sedation and intravenow heparin was given 10000 units 6-hourly.

Over the next $48 \mathrm{hr}$, the patient continued complain of pleuritic and vague upper abdomini pain with anorexia, nausea and an occasional sma vomit.

On the third day she collapsed. The patient was very pale and profoundly shocked with a barefy perceptible blood pressure and pulse. The abdomen was now markedly distended with shifting dullneas and a fluid thrill. At laparotomy, some 3 litres of unclotted blood was evacuated. A normal pregnancy was confirmed. The spleen, of normal dimensions was thickened and roughened on the convex surfigce. The lower pole was lacerated and transfixed by exostosis $2 \frac{1}{2} \mathrm{~cm}$ in length arising from the if border of the 10th rib (Fig. 1). Splenectomy and exostectomy was performed while 6 units of bloos and 2 litres of other fluids was transfused. She made an uncomplicated recovery.

Microscopic examination confirmed laceration the lower pole below an area of capsular thickenin on an otherwise normal spleen.

Seven months later, a healthy male infant was delivered.

\section{Discussion}

In some of the early larger series, the mortality from spontaneous rupture was $10 \%$ (Orloff ang Peskin, 1958) and in the pregnant group maternal mortality was $35 \%$ and that for the fetus $70 \%$ for al types of ruptured spleen (Sparkman, 1958; Buchs baum, 1969; Barnett, 1952). These high figures are ascribed to delay in diagnosis and treatment.

It is likely that so-called 'spontaneous' rupture in fact occurs as a result of capsular injury by the lowep ribs from trivial blunt trauma (coughing and strain ing for instance) either unnoticed by the patient the time, or forgotten since, in the light of subsequed events (Orloff and Peskin, 1958). The spleen, eno larged for any reason, is particularly prone to sucf injury. In our case, the prominent exostosis arising 


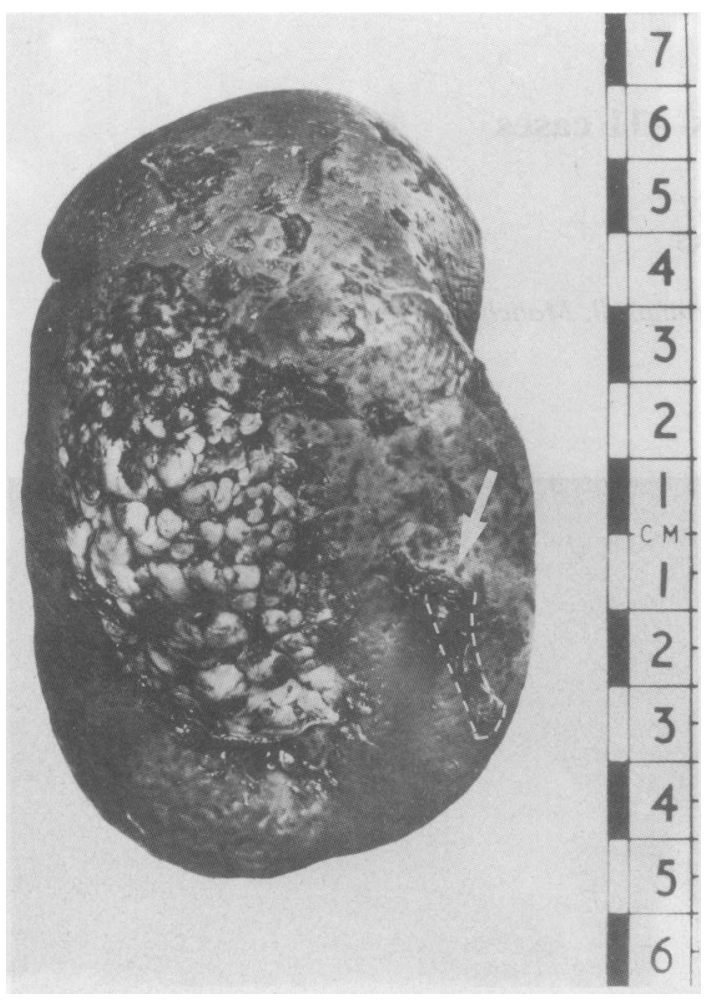

Fig. 1. The convex surface of the spleen to show the roughened capsule. The exostosis (dotted outline) has been replaced in the laceration (arrowed). from the 10th rib had roughened and thickened a circumscribed area of the splenic capsule (Fig. 1) over the years as a result of the respiratory excursions and movement of daily life. Laceration of the unthickened lower pole finally occured during pregnancy, at a time when splenic size, vascularity and position may be altered.

The mortality will only be reduced by awareness of the possibility of spontaneous rupture of the spleen, and prompt surgical intervention.

\section{Acknowledgments}

My thanks to Dr P. Cardew and the Photographic Department for the print and to Miss A. Taft for typing the manuscript.

\section{References}

BARNETT, T. 1952) Rupture of the spleen in pregnancy. Journal of Obstetrics and Gynaecology of the British Empire, 59, 795.

BUCHSBAUM, H. (1969) Splenic rupture in pregnancy. Obstetrics and Gynaecology Survey, 22, 381.

ORLOFF, M. \& PeSKIN, G. (1958) Spontaneous rupture of the normal spleen. A surgical enigma. International Abstracts of Surgery, 106, 1.

SPARKMAN, R. (1958). Rupture of the spleen in pregnancy. American Journal of Obstetrics and Gynecology, 76, 587.

(Accepted 7 December 1982) 